\title{
Dehydrogenation of Methylcyclohexane: Parametric Sensitivity of the Power Law Kinetics
}

\author{
Muhammad R. Usman, ${ }^{1,2}$ David L. Cresswell, ${ }^{1}$ and Arthur A. Garforth ${ }^{1}$ \\ ${ }^{1}$ School of Chemical Engineering and Analytical Science, The University of Manchester, Manchester M60 1QD, UK \\ ${ }^{2}$ Institute of Chemical Engineering and Technology, University of the Punjab, New Campus, Lahore-54590, Pakistan
}

Correspondence should be addressed to Muhammad R. Usman; mrusman.icet@pu.edu.pk

Received 4 June 2013; Accepted 5 July 2013

Academic Editors: D. Cazorla-Amoros, G. D’Errico, F. Lefebvre, and E. A. O’Rear

Copyright (C) 2013 Muhammad R. Usman et al. This is an open access article distributed under the Creative Commons Attribution License, which permits unrestricted use, distribution, and reproduction in any medium, provided the original work is properly cited.

\begin{abstract}
For heterogeneous catalytic reactions, the empirical power law model is a valuable tool that explains variation in the kinetic behavior with changes in operating conditions, and therefore aids in the development of an appropriate and robust kinetic model. In the present work, experiments are performed on $1.0 \mathrm{wt} \% \mathrm{Pt} / \mathrm{Al}_{2} \mathrm{O}_{3}$ catalyst over a wide range of experimental conditions and parametric sensitivity of the power law model to the kinetics of the dehydrogenation of methylcyclohexane is studied. Power law parameters such as order of the reaction, activation energy, and kinetic rate constants are found dependent upon the operating conditions. With $\mathrm{H}_{2}$ in the feed, both apparent order of the reaction and apparent activation energy generally increase with an increase in pressure. The results suggest a kinetic model, which involves nonlinear dependence of rate on the partial pressure of hydrogen and adsorption kinetics of toluene or some intermediate.
\end{abstract}

\section{Introduction}

Dehydrogenation of a cycloalkane such as methylcyclohexane $(\mathrm{MCH})$ is an important model reaction in reforming of naphtha [1]. A typical reformer feedstock has $20-60$ vol\% naphthenes [2], which principally undergo dehydrogenation to aromatics. The dehydrogenation of $\mathrm{MCH}$ is an essential reaction in the methylcyclohexane-toluene-hydrogen (MTH) system for the safe and economical storage and utilization of hydrogen [3]. Moreover, it can be a valuable model reaction in the refining of naphthenic-based heavy crude oils [4]. For heterogeneous catalytic reactions, the empirical power law model is an important tool in providing the variation in the kinetic behavior to elaborate the insight of the kinetics of a reaction and therefore helps in guiding towards the development of an appropriate and robust kinetic model. Kinetics of the $\mathrm{MCH}$ dehydrogenation over supported Pt catalysts has been studied by a number of researchers $[1,4-21]$. However, the variation in kinetic behavior and kinetic parameters (power law index, rate constant, and activation energy) of the dehydrogenation reaction with variation in operating conditions is rarely studied $[19,22]$. Both Jossens and Petersen [22] and Alhumaidan et al. [19] carried out experiments in the presence of hydrogen and analyzed the data with initial rate method. The present study, on the other hand, is designed to conduct a more rigorous and comprehensive kinetic investigation including experiments without hydrogen in the feed over $1.0 \mathrm{wt} \% \mathrm{Pt} / \gamma-\mathrm{Al}_{2} \mathrm{O}_{3}$ catalyst. Based on the power law model, kinetic analysis is carried out in which the effect of the operating conditions on the kinetic parameters of the dehydrogenation is studied.

\section{Experimental}

The experimental setup is shown in Figure 1. The dehydrogenation reactor was a fixed bed reactor made of $1.02 \mathrm{~cm} \mathrm{I.D.}$ stainless tube. $2.01 \mathrm{~g}$ of $1.0 \mathrm{wt} \% \mathrm{Pt} / \gamma-\mathrm{Al}_{2} \mathrm{O}_{3}$ catalyst of the size $-710+425 \mu \mathrm{m}$ were loaded in the reactor. The reactor tube was placed within a three zone tubular furnace in order to maintain the required temperature. $\gamma-\mathrm{Al}_{2} \mathrm{O}_{3}$ of Alfa-Aesar (Johnson-Matthey) was used as a catalyst support. The support had a pore volume of $0.58 \mathrm{~m}^{3} / \mathrm{g}$, median pore diameter of $69 \AA$, and BET surface area of $208 \mathrm{~m}^{2} / \mathrm{g}$. Chloroplatinic 
TABLE 1: Groups formation for the experimental rate data obtained for the dehydrogenation of $\mathrm{MCH}_{\mathrm{Cver}} 1.0 \mathrm{wt} \% \mathrm{Pt} / \gamma-\mathrm{Al}{ }_{2} \mathrm{O}_{3} \mathrm{catalyst}$.

\begin{tabular}{|c|c|c|c|c|c|c|c|}
\hline \multirow{2}{*}{ Group } & \multirow{2}{*}{$N$} & \multicolumn{3}{|c|}{ Feed composition } & \multirow{2}{*}{$T_{w}(\mathrm{~K})$} & \multirow{2}{*}{$p$ (bar) } & \multirow{2}{*}{$W / F_{A 0} \times 10^{-4}(\mathrm{~s} \cdot \mathrm{g}$-cat- $/ \mathrm{mol} \mathrm{MCH})$} \\
\hline & & $y_{A 0}$ & $y_{\mathrm{C} 0}$ & $y_{I 0}$ & & & \\
\hline \multicolumn{8}{|l|}{1} \\
\hline 11 & 21 & 0.106 & 0.893 & 0.001 & $614.2,634.2,653.2$ & 1.013 & $3.11,6.22,12.44$ \\
\hline 21 & 21 & 0.485 & 0.511 & 0.005 & $614.2,634.2,653.2$ & 1.013 & $3.11,6.22,12.44$ \\
\hline 31 & 21 & 0.990 & 0 & 0.010 & $614.2,634.2,653.2$ & 1.013 & $3.11,6.22,12.44$ \\
\hline 41 & 21 & 0.485 & 0 & 0.515 & $614.2,634.2,653.2$ & 1.013 & $3.11,6.22,12.44$ \\
\hline \multicolumn{8}{|l|}{2} \\
\hline 15 & 21 & 0.106 & 0.893 & 0.001 & $614.2,634.2,653.2$ & 5.0 & $3.11,6.22,12.44$ \\
\hline 25 & 21 & 0.485 & 0.511 & 0.005 & $614.2,634.2,653.2$ & 5.0 & $3.11,6.22,12.44$ \\
\hline 45 & 21 & 0.485 & 0 & 0.515 & $614.2,634.2,653.2$ & 5.0 & $3.11,6.22,12.44$ \\
\hline \multicolumn{8}{|c|}{ 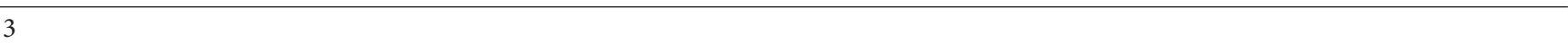 } \\
\hline 19 & 21 & 0.106 & 0.893 & 0.001 & $614.2,634.2,653.2$ & 9.0 & $3.11,6.22,12.44$ \\
\hline 29 & 21 & 0.485 & 0.511 & 0.005 & $614.2,634.2,653.2$ & 9.0 & $3.11,6.22,12.44$ \\
\hline 49 & 21 & 0.485 & 0 & 0.515 & $614.2,634.2,653.2$ & 9.0 & $3.11,6.22,12.44$ \\
\hline
\end{tabular}

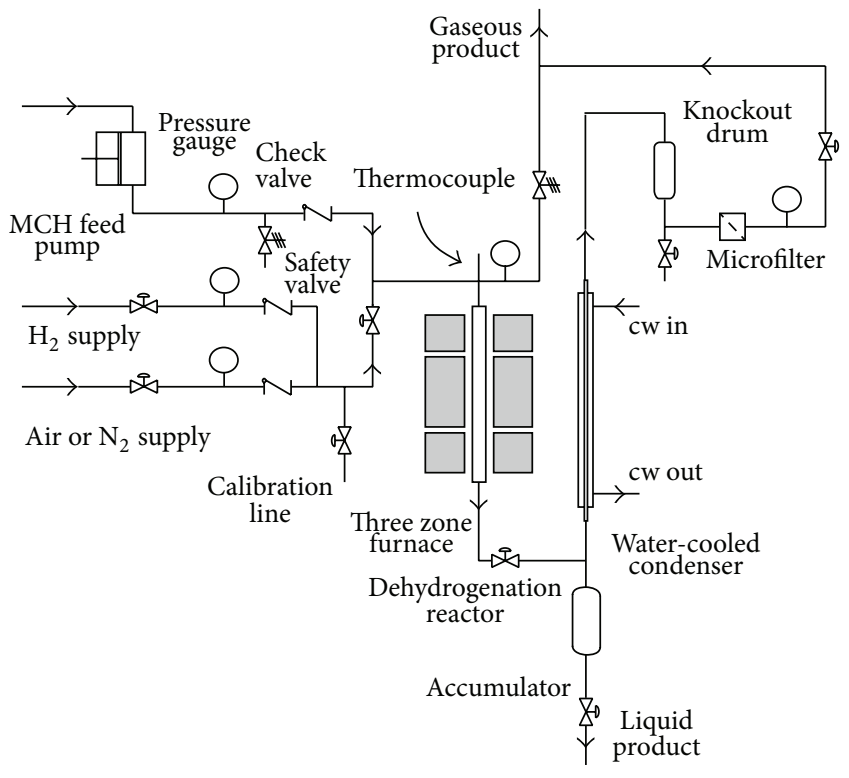

FIGURE 1: Experimental setup.

acid, $\mathrm{H}_{2} \mathrm{PtCl}_{6} \cdot 6 \mathrm{H}_{2} \mathrm{O}$, of Sigma-Aldrich was used as platinum source to impregnate the $\mathrm{Pt}$ metal over the $\gamma-\mathrm{Al}_{2} \mathrm{O}_{3}$ support. The catalyst was calcined and then reduced in situ. Calcination was carried out in air, while hydrogen was used to reduce the catalyst. The total operating pressure and reactor wall temperature were varied in the range of 1.013 to 9.0 bar and 614.2 to $653.2 \mathrm{~K}$, respectively. Molal space time (feed flowrate) was studied between $3.11 \times 10^{4}$ and $12.44 \times 10^{4} \mathrm{~s} \cdot \mathrm{g}$ $\mathrm{cat} / \mathrm{mol}-\mathrm{MCH}$. Feed compositional effect was studied by introducing hydrogen and nitrogen gas. $\mathrm{H}_{2}$ to $\mathrm{MCH}$ and $\mathrm{N}_{2}$ to $\mathrm{MCH}$ molar ratios were studied between $0-8.4$ and $0-1.05$, respectively. Four experimental runs were carried out daily. The first experimental run was initiated with $0.25 \mathrm{~mL} / \mathrm{min}$ $\mathrm{MCH}$, which was followed, respectively, by $0.125 \mathrm{~mL} / \mathrm{min}$ and $0.5 \mathrm{~mL} / \mathrm{min}$. Each of the previous runs lasted for $90 \mathrm{~min}$. The fourth and the last run (for $45 \mathrm{~min}$ only) was the repeat of the first run $(0.25 \mathrm{~mL} / \mathrm{min})$ and facilitated in inspecting the short-term deactivation that had taken place during the course of the dehydrogenation reaction. The products of the dehydrogenation were analyzed in Varian 3400 gas chromatograph containing $100 \mathrm{~m}$ nonpolar capillary column and (BP-5: 5\% phenyl and 95\% dimethylpolysiloxane) equipped with flame ionization detector (FID). The details of the experimental setup and experimental procedure may be found elsewhere [4].

\section{Data Analyses Technique and Basic Equations}

3.1. Grouping of Experimental Data. The experimental data obtained over the $1.0 \mathrm{wt} \% \mathrm{Pt} / \gamma-\mathrm{Al}_{2} \mathrm{O}_{3}$ catalyst is grouped according to the feed composition, pressure, and temperature. Table 1 shows the manner in which the experimental data is grouped. The data collection in groups is carried out in order to highlight trends in the parameter values, to observe the effects of feed composition on a given fit for a specified pressure, and to signify the effects of pressure itself.

3.2. Basic Equations. The dehydrogenation reaction was found highly selective with toluene as the only major product. The kinetic analysis was, therefore, performed for the principal reaction, (1), only:

$$
\mathrm{MCH} \rightleftharpoons \text { Toluene }+3 \mathrm{H}_{2}
$$

The power law kinetics of the following form containing the effect of short-term deactivation is employed [4]:

$$
(-r)=k \cdot\left(p_{\mathrm{A}}-\frac{p_{\mathrm{B}} \cdot p_{\mathrm{C}}^{3}}{K}\right)^{n} \cdot\left(1-k_{d} \cdot t_{d}\right) .
$$

As mentioned in Section 2, the last run was the repeat of the first run $(0.25 \mathrm{~mL} / \mathrm{min})$ and upon examination shows a decrease in the final conversion of methylcyclohexane over the intervening period. To account for such reversible deactivation, time online deactivation constant, $k_{d}$, is introduced in (2). 
The value of the equilibrium constant $K$ was experimentally determined by Schildhauer et al. [23] and is given by

$$
K=3600 \cdot \exp \left(\frac{-217650}{R}\left(\frac{1}{T}-\frac{1}{650}\right)\right)
$$

with $K$ in $\operatorname{bar}^{3}, R$ in $\mathrm{J} \cdot \mathrm{mol}^{-1} \cdot \mathrm{K}^{-1}$, and $T$ in $\mathrm{K}$.

The rate constant $k$ is assumed to follow the Arrhenius temperature dependency and is rearranged in terms of the reference temperature, $T_{r}$, as shown next in (4):

$$
k=k_{r} \cdot \exp \left(B \cdot\left(1-\frac{T_{r}}{T}\right)\right) .
$$

The introduction of $T_{r}$ facilitates in regression of the data and avoids correlation among the parameters [24]. The reference temperature, the central temperature of all the temperatures, is taken as $617.2 \mathrm{~K}$.

The term $B$ in (4) is called the dimensionless activation energy and is given by the expression

$$
B=\frac{E}{R \cdot T_{r}} .
$$

The average temperature $T$ as shown in Figure 2 is calculated using the following formula assuming a parabolic temperature distribution in the radial direction $[4,19]$ :

$$
T=\frac{1}{N} \cdot \sum_{i=1}^{i=N}\left(\frac{T_{z, i}+T_{w}}{2}\right)
$$

where $T_{z, i}$ is the measured temperature at the $i$ th axial position at the centerline in the catalyst bed, $T_{w}$ is the reactor wall temperature, and $N$ is the number of axial temperature measurements.

The following differential equation is fitted against the experimental data, and four kinetic variables $n, k_{r}, B$, and $k_{d}$ are collectively estimated:

$$
\begin{aligned}
\frac{d X}{d Y} & =(-r) \times 10^{5} \\
& =k \times 10^{5} \cdot\left(p_{\mathrm{A}}-\frac{p_{\mathrm{B}} \cdot p_{\mathrm{C}}^{3}}{K}\right)^{n} \cdot\left(1-k_{d} \cdot t_{d}\right),
\end{aligned}
$$

where

$$
Y=10^{-5} \times \frac{W}{F_{A 0}} .
$$

3.3. Regression Procedure. The regression of the kinetic data is carried out using a FORTRAN code, and the following objective function, the sum of squares of the errors (SSE) is minimized:

$$
\mathrm{SSE}=\sum_{i=1}^{i=N}\left(X_{i, \mathrm{obs}}-X_{i, \mathrm{mod}}\right)^{2}
$$

where $X_{i, \mathrm{obs}}$ is the $i$ th measured or observed value of conversion, $X_{i, \text { mod }}$ is the corresponding value calculated from (7), and $N$ is the total number of data points.

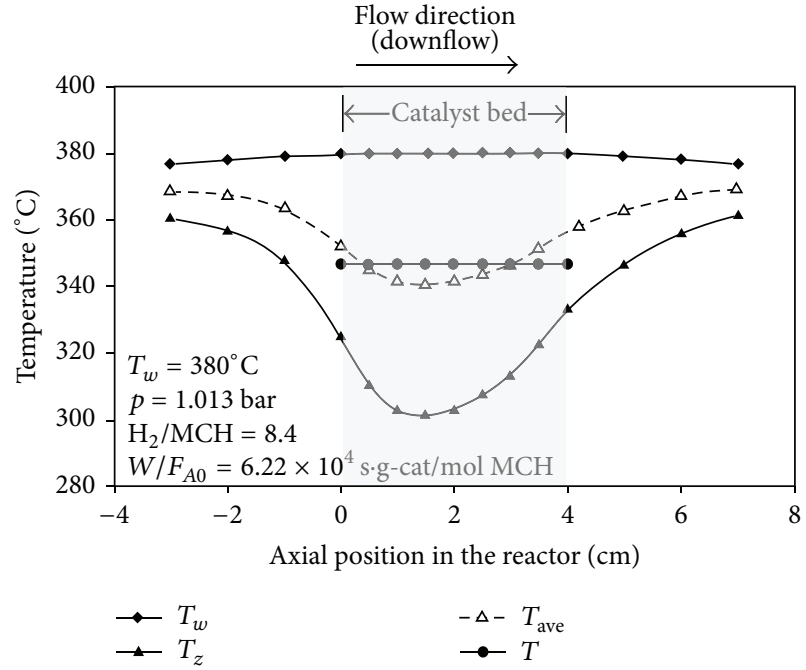

FIGURE 2: A typical set of temperature profiles in the dehydrogenating reactor. $T_{w}=$ reactor wall temperature; $T_{z}=$ measured centerline temperatures in the reactor; $T_{\mathrm{ave}}=$ local average temperatures between the previous two values, and $T=$ overall average catalyst bed temperature.

\section{Results and Discussion}

Table 2 provides the parameter values and overall statistics obtained during the regression of the data in the individual groups. On the other hand, Figure 3 provides a relationship, for the selected groups, between the measured values of conversion, $X_{\mathrm{obs}}$, and model values, $X_{\mathrm{mod}}$, to visualize the goodness of the fit. A graphical version of the effect of pressure and composition on the kinetic parameters is shown in Figures 4, 5 , and 6 .

4.1. 1.013 Bar Pressure. It is obvious that each individual group is relatively better fitted at 1.013 bar by the power law model giving SSE values always less than 0.00989 and the corresponding values of $\operatorname{Adj}\left(R^{2}\right)$ not less than 0.983 .

Inspecting orders of the reaction for the individual groups fitted, it is apparent that the order of the reaction decreases from group 11 to group 21 and then remains virtually the same for group 31 and group 41. This observation is crucial in explaining the fact that the concentration of hydrogen and not the $\mathrm{MCH}$ concentration in the feed is responsible for change in the order of the reaction. The highest value of the order of the reaction is the result for group 11 in which the concentration of hydrogen is the maximum, that is, $89.3 \mathrm{~mol} \%$ in the feed. A comparison of the results for group 21 and group 41 allows a direct assessment of the effects of replacing $\mathrm{H}_{2}$ with $\mathrm{N}_{2}$ in the feed, while maintaining a constant partial pressure of $\mathrm{MCH}$. Calculating initial rates at $T=$ $T_{r}=617.2 \mathrm{~K}$, the initial rate of the reaction decreases from $8.0 \times 10^{-5}$ to $4.09 \times 10^{-5} \mathrm{~mol} \cdot \mathrm{g}$-cat ${ }^{-1} \cdot \mathrm{s}^{-1}$ on replacing $\mathrm{H}_{2}$ by $\mathrm{N}_{2}$. This observation should not be a result of irreversible loss of activity, since the periodic activity test showed no long-term activity loss. These observations suggest that $\mathrm{H}_{2}$, a product of the reaction, appears to act as a promoter and has 
TABLE 2: Results of the power law regression for the data in individual groups.

\begin{tabular}{lcccccc}
\hline Group & $n$ & $\begin{array}{c}E \\
\left(\mathrm{~kJ} \cdot \mathrm{mol}^{-1}\right)\end{array}$ & $\begin{array}{c}(-r)_{0} \times 10^{5} \\
\left(\mathrm{~mol} \mathrm{MCH} \cdot \mathrm{g}-\mathrm{cat}^{-1} \cdot \mathrm{s}^{-1}\right)\end{array}$ & $\begin{array}{c}k_{d} \\
\text { day }^{-1}\end{array}$ & SSE & Adj $\left(R^{2}\right)$ \\
\hline 11 & - & 54.55 & 4.14 & 1.35 & 0.00519 & 0.992 \\
21 & 0.99 & 58.83 & 8.00 & 1.68 & 0.00989 & 0.983 \\
31 & 0.78 & 54.55 & 8.29 & 1.75 & 0.00831 & 0.986 \\
41 & 0.71 & 4.09 & 1.67 & 0.00648 & 0.991 \\
15 & 0.69 & 53.37 & 0.30 & 0.69 & 0.00545 & 0.992 \\
25 & 1.51 & 138.7 & 0.76 & 1.21 & 0.00682 & 0.989 \\
45 & 1.21 & 117.2 & 1.27 & 1.67 & 0.00247 & 0.996 \\
19 & 0.98 & 83.04 & 0.08 & 0.81 & 0.00213 & 636.26 \\
29 & 1.30 & 93.70 & 0.15 & 0.99 & 0.00255 & 0.995 \\
49 & 1.29 & 119.5 & 0.38 & 2.01 & 0.00378 & 0.995 \\
\hline
\end{tabular}
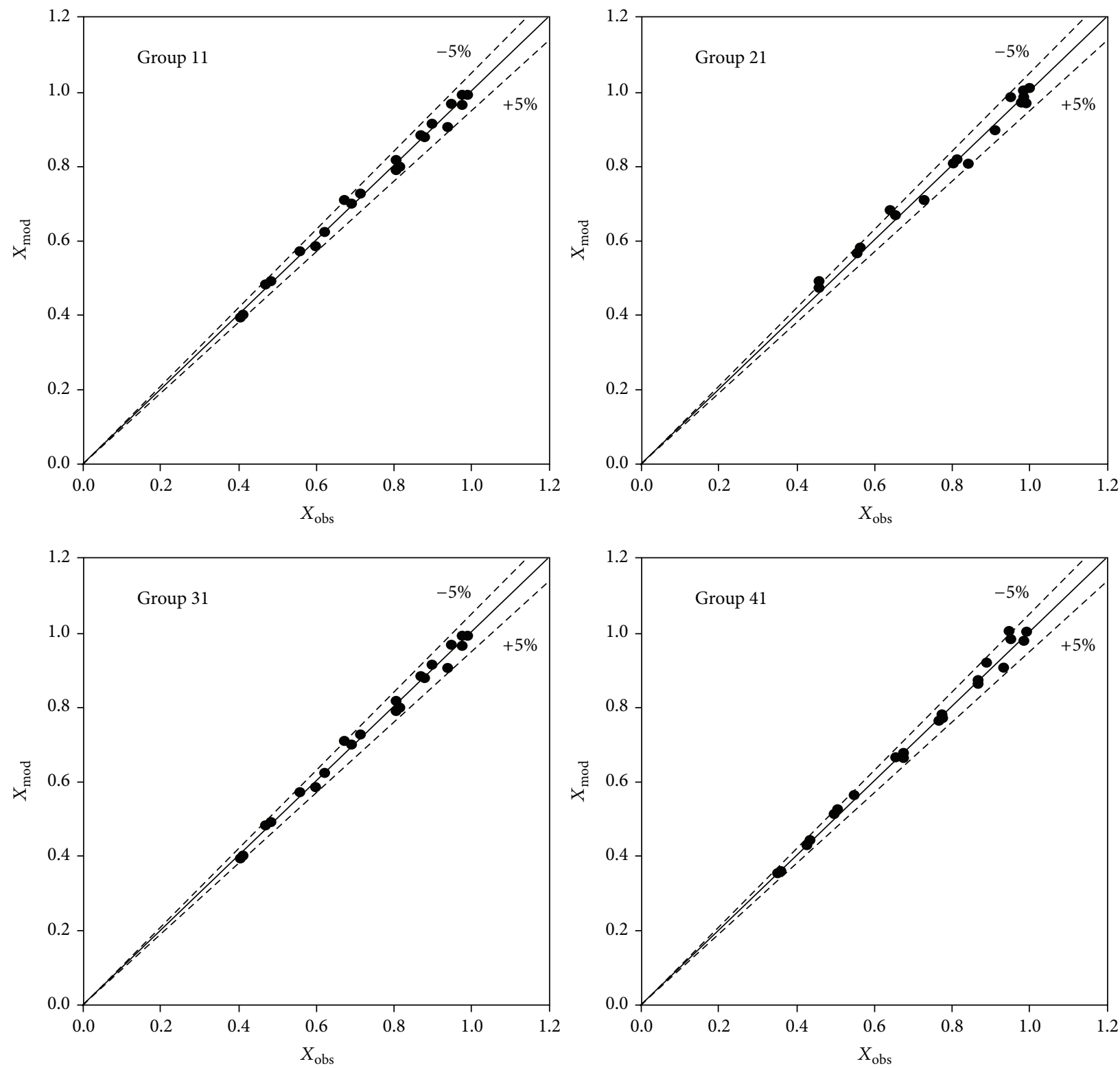

FIGURE 3: Scatter diagrams for the power law model relating observed and model values of conversions at 1.013 bar. 


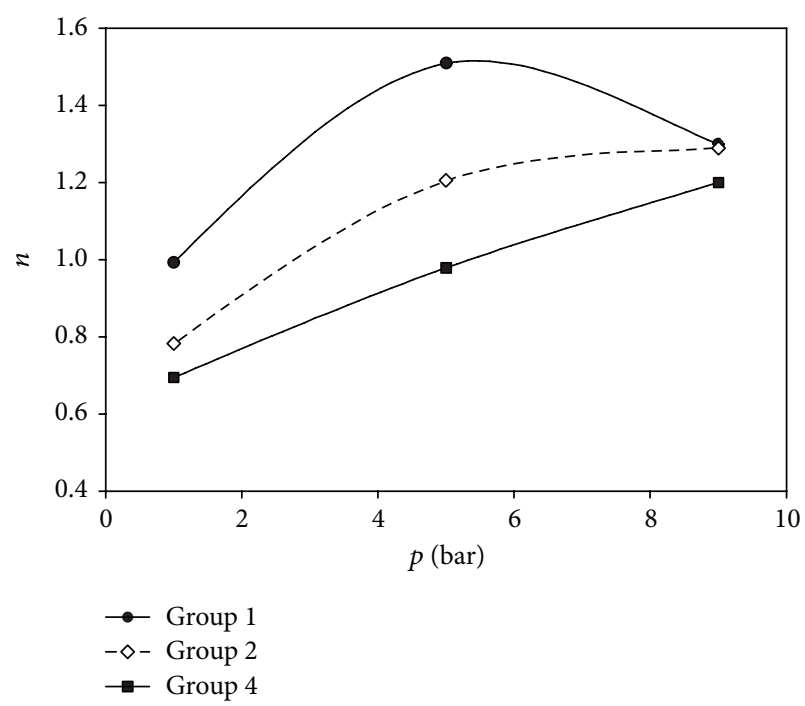

FIGURE 4: Effect of pressure on the order of the reaction for the power law kinetics.

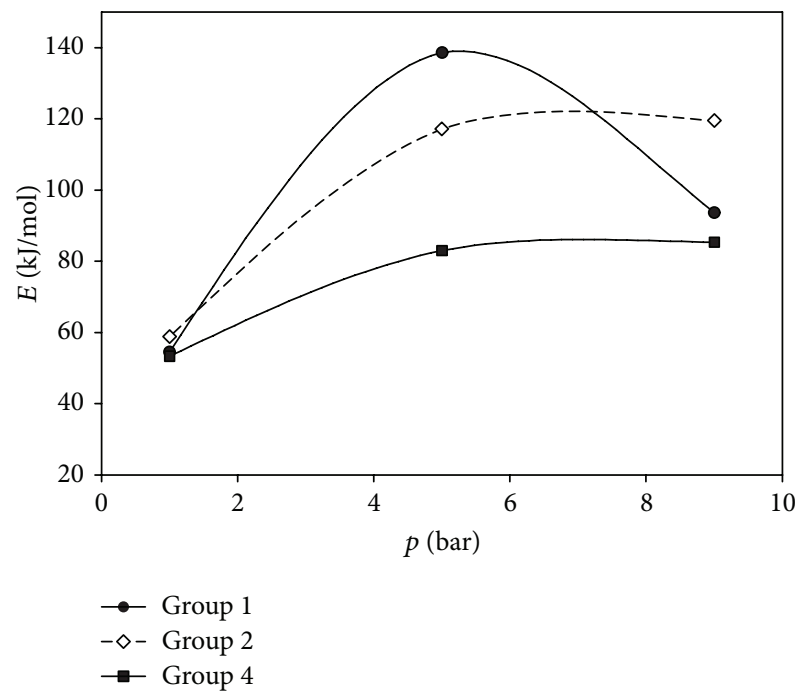

FIGURE 5: Effect of pressure on the activation energy of the reaction for the power law kinetics.

a positive effect towards the kinetics of the reaction, at least at atmospheric pressure. The observation may be explained on the basis of relatively higher toluene inhibition under the conditions when no hydrogen is in the feed. This same promotion in the presence of $\mathrm{H}_{2}$ and toluene inhibition at atmospheric pressure was also observed by other researchers in the field $[21,22,25]$. A reaction order close to unity for group 11 suggests a low $\mathrm{MCH}$ coverage. However, a decrease in the order of the reaction with decreasing $\mathrm{H}_{2}$ in the feed suggests an increase in coverage of $\mathrm{MCH}$. Combining the previous statements, it is concluded that the presence of $\mathrm{H}_{2}$ may be helpful in replacing the strongly adsorbed products species, which otherwise cover the active surface. The activation energy parameter, $B$, remains more or less the same, and the apparent activation energy lies within 53.4 to $58.8 \mathrm{~kJ} / \mathrm{mol}$.

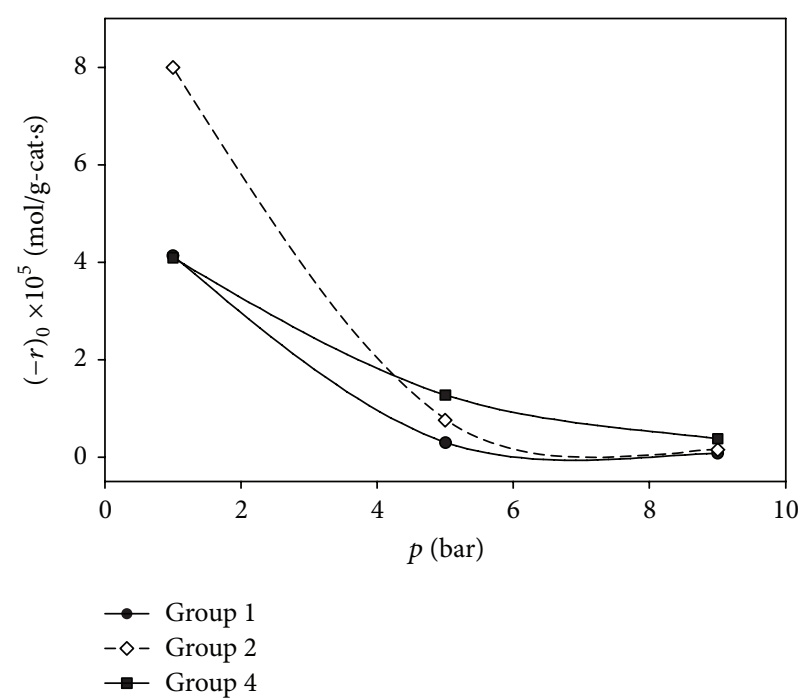

FIGURE 6: Effect of pressure on the initial rate of the reaction for the power law kinetics.

A wide range of apparent activation energies is reported in the literature. The values previously given tend to be towards the bottom of the range. The deactivation rate constant, $k_{d}$, is always significant, confirming the importance of including the short-term deactivation.

4.2. 5.0 Bar Pressure. Also, at $p=5.0$ bar, individual groups are fitted very well. It is apparent for group 15 and group 25 in Table 2 that $n>1$. This seems unlikely on physical grounds. However, the manifestation of an apparent order $n>1$ can be reconciled with strong chemisorption of one or both of the reaction products toluene or hydrogen, or of reaction intermediates, such as methylcyclohexenes or methylcyclohexadienes. The former intermediate, methylcyclohexene, was observed in low concentrations in the condensate, corresponding to intermediate levels of conversion of methylcyclohexane. Methylcyclohexadienes, on the other hand, have never been observed. This is not to say, however, that they are not formed on the catalyst surface. It is obvious that the apparent order $n$ is significantly greater at 5.0 bar than at 1.013 bar, when hydrogen is in the feed. Langmuir-Hinshelwood-Hougen-Watson (LHHW) postulates, on the other hand, predict a decreasing apparent order $n$ with increasing pressure, consistent with an increasing surface coverage of methylcyclohexane.

The values of the activation energy are considerably higher for group 15 and group 25. This shows that pressure has a significant effect on the activation energy of the reaction when $\mathrm{H}_{2}$ is present in the feed. Comparing group 25 and group 45 , in contrast to 1.013 bar results, no promotion of hydrogen is observed. The initial rate of reaction, $\left(-r_{0}\right) \times 10^{5}$, is reduced by up to an order of magnitude on increasing the pressure from 1.013 bar to 5.0 bar, which suggests strong product retarding effects. On average, the value of the deactivation constant, $k_{d}$, is less than that for 1.013 bar and especially for group 15 (highest hydrogen feed concentration), 
where the $95 \%$ confidence interval involves zero, suggesting the parameter $k_{d}$ becomes insignificant.

4.3. 9.0 Bar Pressure. In all the cases, at 9.0 bar, an extremely good individual group fit of the data is found with $\operatorname{Adj}\left(R^{2}\right)>$ 0.99 . Similar to the results at $1.013 \mathrm{bar}$ and $5.0 \mathrm{bar}$, the power law model parameters appear to be group dependent. The value of $n$ remains virtually the same in group 19, group 29, and group 49; a slight increase, however, is noticeable in the groups containing $\mathrm{H}_{2}$. The same observation is observed at 5.0 bar, however, with a greater variation. The order of the reaction $n>1.0$ can be described in the same way as explained previously. The activation energy is found to be quite high, greater than $85 \mathrm{~kJ} / \mathrm{mol}$ in all the individual group listings. Comparing group 29 and group 49, an increased initial rate and lower activation energy are observed for group 49. Similarly, a low value of the deactivation constant $\left(k_{d}\right)$ is observed when hydrogen is in the feed, which confirms the beneficial effects of hydrogen in maintaining the catalyst activity. A high value of the deactivation constant $\left(k_{d}\right)$ in the absence of hydrogen may be explained on the basis of the formation of unsaturated intermediates which act as coke precursors.

The previous discussion reveals that at each pressure, parameters are found to be group dependent. This is summarized graphically in Figures 4 to 6 . When $\mathrm{H}_{2}$ is in the feed, both apparent order of the reaction and apparent activation energy have increased values at high pressures. Actually, for higher concentrations of hydrogen in the feed, these pass through a maximum and then fall back, while for lower hydrogen feed concentrations, the values increase and then remain almost same. An increased value of activation energy provides the clue of some strongly adsorbed components that require higher activation energies of desorption to desorb into the gas phase. A higher order of the reaction, greater than unity, at increased pressure somewhat confirms this hypothesis. The initial rates of reaction at $T=T_{r}=617.2 \mathrm{~K}$ tend to decrease with pressure for all the groups. This kind of behavior is less common, though it is compatible with an LHHW dual-site kinetic model. The effect of hydrogen at higher pressures, (say) 9.0 bar, seems to be vanishing as values of parameters somehow approach each other. Comparing group 2 at different pressures, it is observed that at low pressures, a promotion of $\mathrm{H}_{2}$ is observed as mentioned earlier, however, at increased pressure values, in fact, $\mathrm{H}_{2}$ adversely affects the rate which may be manifested that reverse reaction is important at higher pressures than at 1.013 bar or the excess $\mathrm{H}_{2}$ in the feed may be involved in the associative adsorption of some products species which otherwise are gaseous products. Another possibility that at high pressures, hydrogen may be competing for the active adsorption sites and therefore lowering the rates of the reaction may not be ruled out. This effect of hydrogen was observed to be more pronounced at 5.0 bar than at 9.0 bar.

In the overall discussion, it may be summarized that the partial pressures of hydrogen and $\mathrm{MCH}$ and adsorption of $\mathrm{MCH}$ are found to be important contributors at atmospheric pressure, while partial pressures of $\mathrm{H}_{2}$ and adsorption of hydrogen and the other major product (toluene) are found important at higher pressures with adsorption of hydrogen less pronounced. This suggests a kinetic equation that includes the effects of partial pressure of $\mathrm{MCH}$ and hydrogen and adsorption kinetics of $\mathrm{MCH}$, hydrogen, and toluene. As with pressures, the initial rates are decreased nonlinearly, so need is there for a term in the denominator that constitutes product of square or cube of the partial pressure of hydrogen (nonlinear dependence of hydrogen partial pressure) and some parameter representing adsorption kinetics of at least one of the major products other than hydrogen, that is, toluene. The best-fit kinetic rate model (based on LangmuirHinshelwood-Hougen-Watson single-site kinetics with loss of first hydrogen as the rate controlling step) of the overall experimental data as carried out in our previous study is shown in (10) [4]. Equation (10) clearly shows the strong nonlinear dependence of hydrogen presence and adsorption kinetics of toluene on the rate of the reaction:

$$
\begin{gathered}
(-r)=\frac{k \cdot K_{\mathrm{A}} \cdot p_{\mathrm{A}} \cdot\left(1-\left(\left(p_{\mathrm{B}} \cdot p_{\mathrm{C}}^{3}\right) /\left(K \cdot p_{\mathrm{A}}\right)\right)\right)}{1+K_{\mathrm{A}} \cdot p_{\mathrm{A}}+K_{\mathrm{B}} \cdot p_{\mathrm{B}}+K^{\prime} \cdot p_{\mathrm{B}} \cdot p_{\mathrm{C}}^{2}} \\
\cdot\left(1-k_{d} \cdot t_{d}\right), \\
K^{\prime}=K_{r}^{\prime} \cdot \exp \left(B^{\prime} \cdot\left(1-\frac{T_{r}}{T}\right)\right), \\
B^{\prime}=\frac{\Delta h^{\prime}}{R \cdot T_{r}} .
\end{gathered}
$$

\section{Conclusions}

Using power law kinetics, the limited data in individual groups is fitted remarkably well, and at each pressure, parameters are found to be group dependent. With $\mathrm{H}_{2}$ in the feed both apparent order of the reaction and apparent activation energy generally increase with pressure. At atmospheric pressure with $\mathrm{H}_{2}$ in the feed, a promotion in the rate of the dehydrogenation reaction is observed. However, at increased pressures, $\mathrm{H}_{2}$ adversely affects the rate. The results suggest a kinetic model, which involves nonlinear dependence of rate on the partial pressure of hydrogen and adsorption kinetics of toluene or some intermediate.

\section{Nomenclature}

B: Dimensionless activation energy

E: Activation energy, J/mol

$F_{A 0}$ : Initial molar flow rate of $\mathrm{MCH}, \mathrm{mol} / \mathrm{s}$

$\Delta h^{\prime}$ : Lumped heat of adsorption, $\mathrm{J} / \mathrm{mol}$

$k$ : Rate constant for the $\mathrm{MCH}$ dehydrogenation reaction, $\mathrm{mol} \cdot \mathrm{kg}^{-1} \cdot \mathrm{s}^{-1} \cdot \mathrm{bar}^{-1}$ for (2) and $\mathrm{mol} \cdot \mathrm{kg}^{-1} \cdot \mathrm{s}^{-1}$ for (10)

$k_{d}$ : Apparent short-term deactivation constant, $\mathrm{s}^{-1}$

$k_{r}$ : Rate constant at the reference temperature, $\mathrm{mol} \cdot \mathrm{kg}^{-1} \cdot \mathrm{s}^{-1} \cdot \mathrm{bar}^{-n}$

$K: \quad$ Equilibrium constant of $\mathrm{MCH}$ dehydrogenation reaction, $\mathrm{Pa}^{3}$

$K_{\mathrm{A}}$ : Adsorption equilibrium constant for methylcyclohexane, $\mathrm{Pa}^{-1}$

$K_{\mathrm{B}}$ : Adsorption equilibrium constant for toluene, $\mathrm{Pa}^{-1}$ 
$K^{\prime}$ : Lumped equilibrium constant, that is, the ratio of $K_{\mathrm{B}}$ to the product of surface equilibrium constants of the dehydrogenation of methylcyclohexene to methylcyclohexadiene and methylcyclohexadiene to toluene in the single-site surface reaction mechanism, $\mathrm{Pa}^{-3}$

$K_{r}^{\prime}$ : $\quad$ Lumped adsorption equilibrium constant defined at $T_{r}, \mathrm{~Pa}^{-3}$

$n$ : $\quad$ Order of the reaction

$N$ : Number of data points

$p$ : $\quad$ Pressure, $\mathrm{Pa}$

$p_{\mathrm{A}}$ : Partial pressure of methylcyclohexane, $\mathrm{Pa}$

$p_{\mathrm{B}}$ : $\quad$ Partial pressure of toluene, $\mathrm{Pa}$

$p_{\mathrm{C}}$ : $\quad$ Partial pressure of hydrogen, $\mathrm{Pa}$

$(-r)$ : Rate of the dehydrogenation reaction, $\mathrm{mol} \cdot \mathrm{kg}^{-1} \cdot \mathrm{s}^{-1}$

$(-r)_{0}$ : Initial rate of the dehydrogenation reaction, $\mathrm{mol} \cdot \mathrm{kg}^{-1} \cdot \mathrm{s}^{-1}$

$R: \quad$ Universal gas constant, $\mathrm{J} \cdot \mathrm{mol}^{-1} \cdot \mathrm{K}^{-1}$

$t_{d}$ : Online reaction deactivation time, $\mathrm{s}$

$T: \quad$ Temperature, $\mathrm{K}$

$T_{\text {ave }}$ : Local average temperature defined in Figure 2, $\mathrm{K}$

$T_{r}$ : $\quad$ Reference temperature, $\mathrm{K}$

$T_{w}$ : $\quad$ Reactor wall temperature, $\mathrm{K}$

$T_{z}$ : Temperature at any position in the axial direction, $\mathrm{K}$

$W: \quad$ Weight of catalyst, $\mathrm{kg}$

$X: \quad$ Conversion (fractional conversion) of $\mathrm{MCH}$

$X_{\text {mod }}$ : Model or calculated conversion of $\mathrm{MCH}$

$X_{\text {obs }}$ : Observed or measured conversion of $\mathrm{MCH}$

$y_{\mathrm{A} 0}$ : Initial mole fraction of $\mathrm{MCH}$ in the vapor phase

$y_{\mathrm{C} 0}$ : Initial mole fraction of hydrogen in the vapor phase

$y_{I 0}$ : Initial mole fraction of inert in the vapor phase.

\section{Acknowledgment}

Muhammad R. Usman would like to acknowledge the Higher Education Commission of Pakistan for funding the research.

\section{References}

[1] K. Jothimurugesan, S. Bhatia, and R. D. Srivastava, "Kinetics of dehydrogenation of methylcyclohexane over a platinum-rhenium-aluminium catalyst in the presence of added hydrogen," Industrial \& Engineering Chemistry Fundamentals, vol. 24, no. 4, pp. 433-438, 1985.

[2] J. H. Gary and G. E. Handwerk, Petroleum Refining: Technology and Economics, Marcel Dekker, New York, NY, USA, 4th edition, 2001.

[3] M. R. Usman and D. L. Cresswell, "Options for on-board use of hydrogen based on the Methylcyclohexane-Toluene-Hydrogen system," International Journal of Green Energy, vol. 10, pp. 177189, 2013.

[4] M. Usman, D. Cresswell, and A. Garforth, "Detailed reaction kinetics for the dehydrogenation of methylcyclohexane over Pt catalyst," Industrial and Engineering Chemistry Research, vol. 51, no. 1, pp. 158-170, 2012.
[5] J. H. Sinfelt, H. Hurwitz, and R. A. Shulman, "Kinetics of methylcyclohexane dehydrogenation over Pt- $\mathrm{Al}_{2} \mathrm{O}_{3}$," The Journal of Physical Chemistry, vol. 64, no. 10, pp. 1559-1562, 1960.

[6] A. W. Ritchie and A. C. Nixon, "Dehydrogenation of methylcyclohexane over a platinum-alumina catalyst in absence of added hydrogen," Industrial \& Engineering Chemistry Product Research and Development, vol. 5, no. 1, pp. 59-64, 1966.

[7] A. Corma, R. Cid, and A. Lopez Agudo, "Catalyst decay in the kinetics of methylcyclohexane dehydrogenation over Pt-NaY zeolite," The Canadian Journal of Chemical Engineering, vol. 57, no. 5, pp. 638-642, 1979.

[8] A. Touzani, D. Klvana, and G. Bélanger, "Dehydrogenation of methylcyclohexane on the industrial catalyst: kinetic study," Studies in Surface Science and Catalysis, vol. 19, pp. 357-364, 1984.

[9] M. A. Pacheco and E. E. Petersen, "Reaction kinetics of methylcyclohexane dehydrogenation over a sulfided $\mathrm{Pt}+\mathrm{Re} / \mathrm{Al}_{2} \mathrm{O}_{3}$ reforming catalyst," Journal of Catalysis, vol. 96, no. 2, pp. 507516, 1985.

[10] P. A. van Trimpont, G. B. Marin, and G. F. Froment, "Kinetics of methylcyclohexane dehydrogenation on sulfided commercial platinum/alumina and platinum-rhenium/alumina catalysts," Industrial \& Engineering Chemistry Fundamentals, vol. 25, no. 4, pp. 544-553, 1986.

[11] A. K. Pal, M. Bhowmick, and R. D. Srivastava, "Deactivation kinetics of platinum-rhenium re-forming catalyst accompanying the dehydrogenation of methylcyclohexane," Industrial \& Engineering Chemistry Process Design and Development, vol. 25, no. 1, pp. 236-241, 1986.

[12] J. Chaouki, A. Touzani, D. Klvana, J. P. Bournonville, and G. Bélanger, "Déshydrogénation du Méthylcyclohexane sur le Catalyseur Industriel Pt-Sn $/ \mathrm{A}_{2} \mathrm{O}_{3}$," Revue de l'Institut Français du Pétrole, vol. 43, no. 6, pp. 873-881, 1988.

[13] M. El-Sawi, F. A. Infortuna, P. G. Lignola, A. Parmaliana, F. Frusteri, and N. Giordano, "Parameter estimation in the kinetic model of methylcyclohexane dehydrogenation on a $\mathrm{Pt}-\mathrm{Al}_{2} \mathrm{O}_{3}$ catalyst by sequential experiment design," The Chemical Engineering Journal, vol. 42, no. 3, pp. 137-144, 1989.

[14] M.-R. Chai and K. Kawakami, "Kinetic model and simulation for catalyst deactivation during dehydrogenation of methylcyclohexane over commercial Pt-, PtRe- and presulfided PtRe$\mathrm{Al}_{2} \mathrm{O}_{3}$ catalysts," Journal of Chemical Technology and Biotechnology, vol. 51, no. 3, pp. 335-345, 1991.

[15] R. H. Manser Sonderer, Methylcyclohexane dehydrogenation kinetics, reactor design and simulation for a hydrogen powered vehicle [Ph.D. thesis], Swiss Federal Institute of Technology, 1992.

[16] G. Maria, A. Marin, C. Wyss et al., "Modelling and scaleup of the kinetics with deactivation of methylcyclohexane dehydrogenation for hydrogen energy storage," Chemical Engineering Science, vol. 51, no. 11, pp. 2891-2896, 1996.

[17] J. H. Sinfelt, "The turnover frequency of methylcyclohexane dehydrogenation to toluene on a Pt reforming catalyst," Journal of Molecular Catalysis A, vol. 163, no. 1-2, pp. 123-128, 2000.

[18] D. E. Tsakiris, Catalytic production of hydrogen from liquid organic hydride [Ph.D. thesis], The University of Manchester, 2007.

[19] F. Alhumaidan, D. Cresswell, and A. Garforth, "Kinetic model of the dehydrogenation of methylcyclohexane over monometallic and bimetallic Pt catalysts," Industrial and Engineering Chemistry Research, vol. 50, no. 5, pp. 2509-2522, 2011. 
[20] M. R. Usman, "Methylcyclohexane dehydrogenation over commercial $0.3 \mathrm{Wt} \% \mathrm{Pt} / \mathrm{Al}_{2} \mathrm{O}_{3}$ catalyst," Proceedings of the Pakistan Academy of Sciences, vol. 48, no. 1, pp. 13-17, 2011.

[21] M. R. Usman, R. Aslam, and F. Alotaibi, "Hydrogen storage in a recyclable organic hydride: kinetic modeling of methylcyclohexane dehydrogenation over $1.0 \mathrm{wt} \% \mathrm{Pt} / \theta-\mathrm{Al}_{2} \mathrm{O}_{3}$," Energy Sources A, vol. 33, no. 24, pp. 2264-2271, 2011.

[22] L. W. Jossens and E. E. Petersen, "Fouling of a platinum reforming catalyst accompanying the dehydrogenation of methyl cyclohexane," Journal of Catalysis, vol. 73, no. 2, pp. 377-386, 1982.

[23] T. H. Schildhauer, E. Newson, and S. Müller, “The equilibrium constant for the methylcyclohexane-toluene system," Journal of Catalysis, vol. 198, no. 2, pp. 355-358, 2001.

[24] J. R. Kittrell, "Mathematical modeling of chemical reactions," Advances in Chemical Engineering, vol. 8, pp. 97-183, 1970.

[25] J. C. Rohrer and J. H. Sinfelt, "Interaction of hydrocarbons with Pt- $\mathrm{Al}_{2} \mathrm{O}_{3}$ in the presence of hydrogen and helium," The Journal of Physical Chemistry, vol. 66, no. 6, pp. 1193-1194, 1962. 

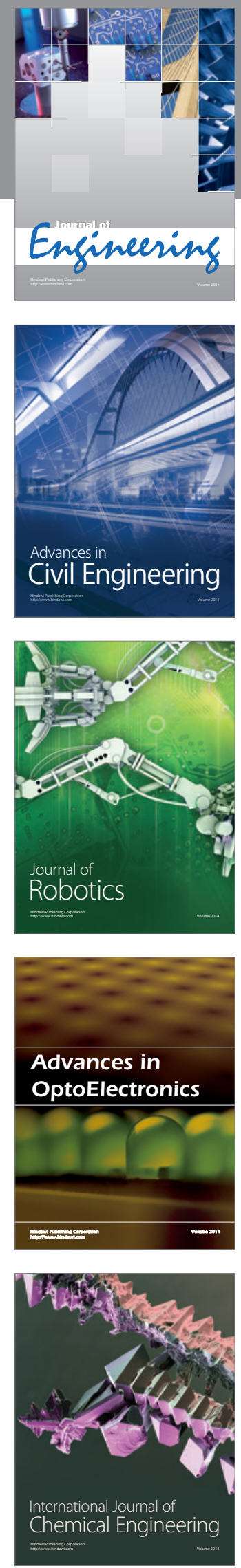

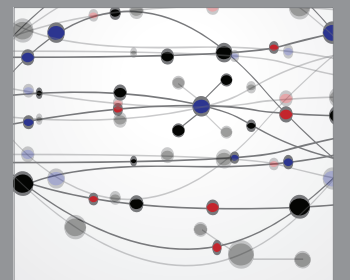

The Scientific World Journal
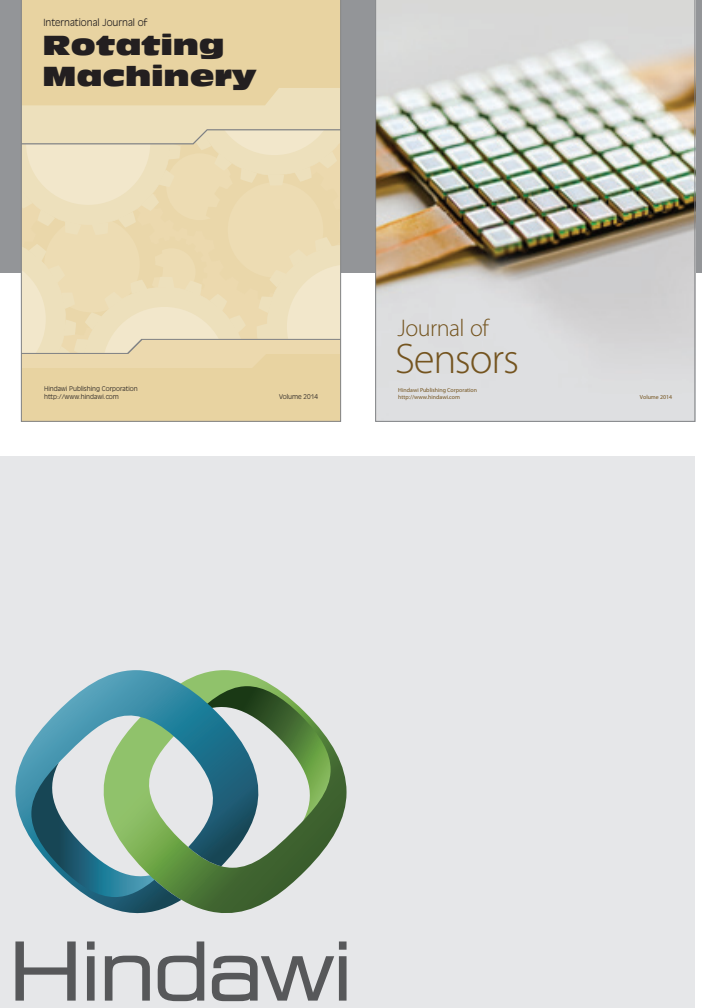

Submit your manuscripts at http://www.hindawi.com
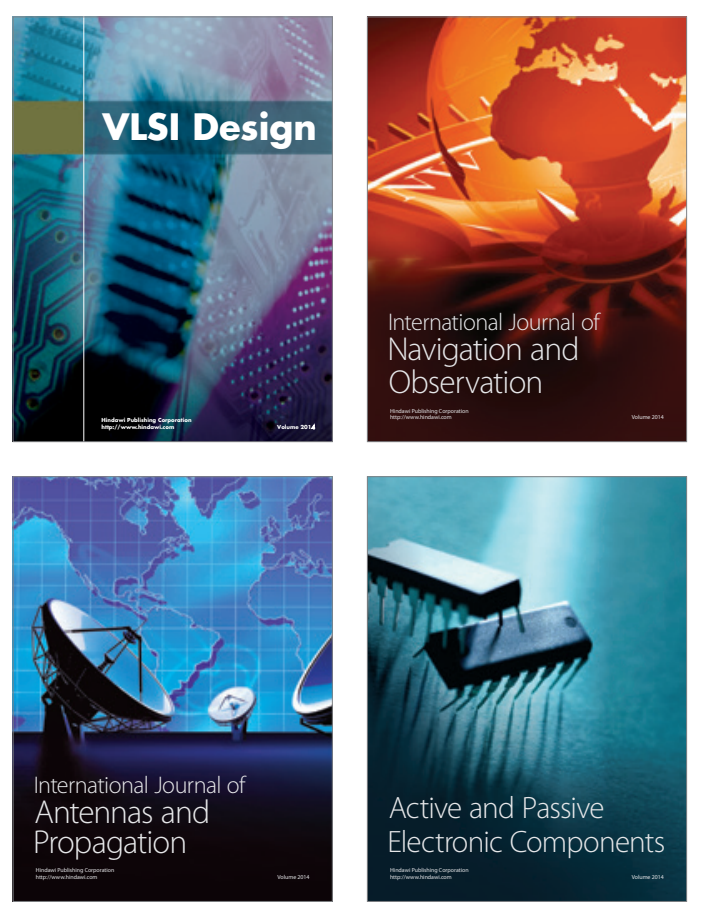
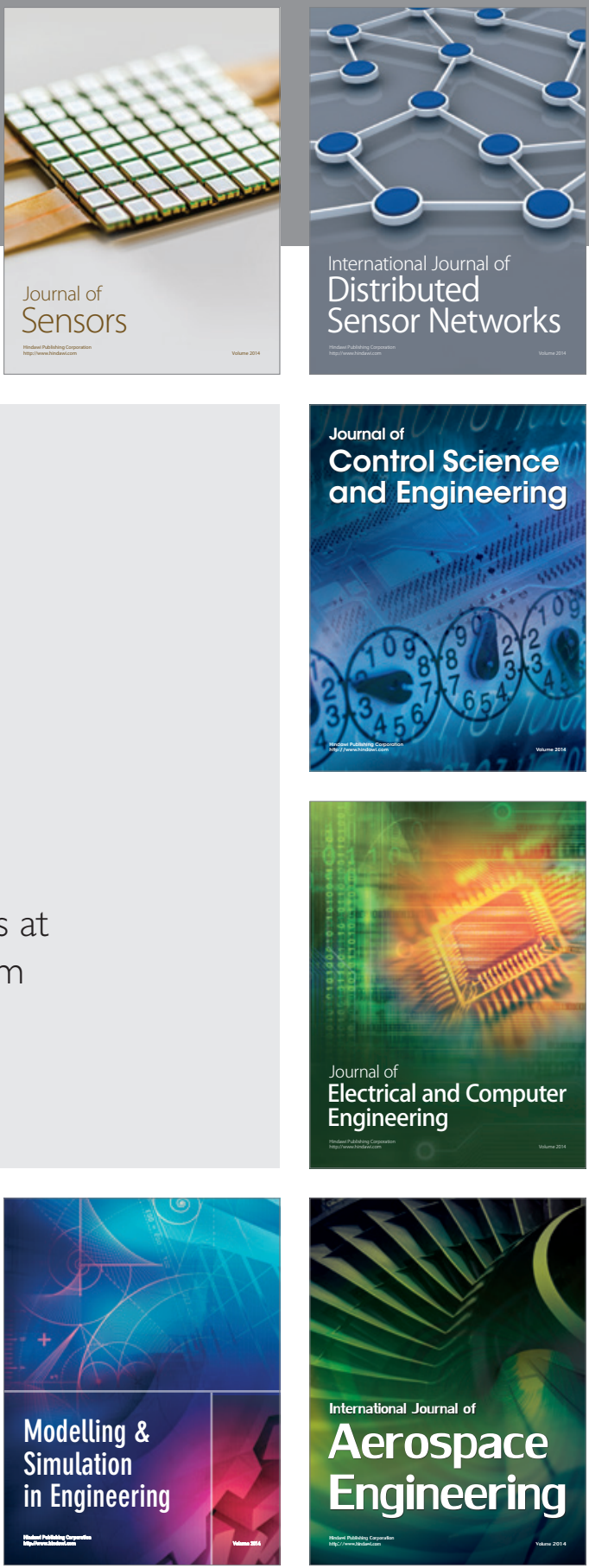

Journal of

Control Science

and Engineering
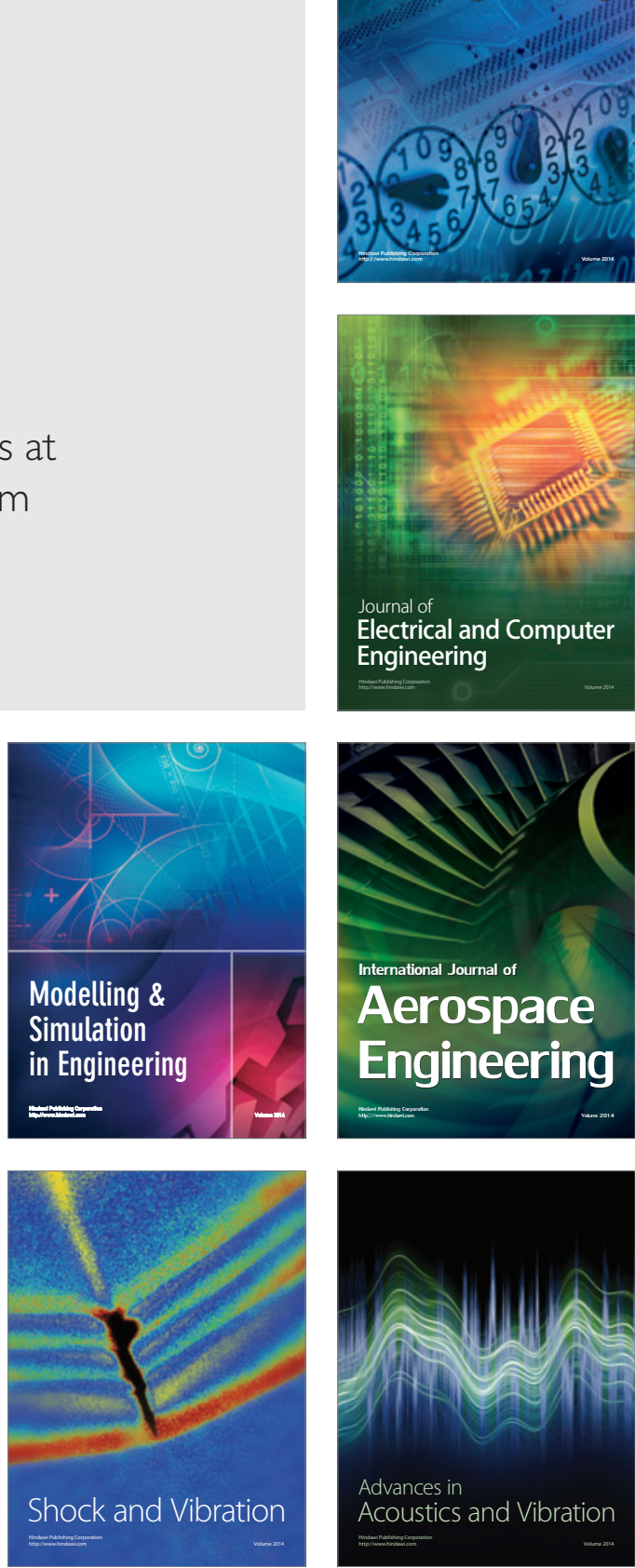